\title{
A NOTE ON NAMES AND THEIR SPELLINGS
}

For Japanese names and places, romanization is based upon the modified Hepburn system, with the exception of Kobe and Tokyo, with surnames placed before given names as is the practice in Japan. For Korean names and places, romanization is based upon the McCuneReischauer system, with the exception of Seoul, and surnames are placed before given names, as is the practice in Korea. There are, however, a number of Koreans in the United States who have chosen alternate spellings of their names and who give their surnames last, in the Western style. There are other Korean names written in English whose Chinese characters are unknown to the writer, making it impossible to create the McCune-Reischauer spellings. In such cases, Korean names will sometimes appear at variance with the McCune-Reischauer system, and given names will sometimes precede surnames. 